\title{
PAPER
}

\section{Autonomic nervous system testing may not distinguish multiple system atrophy from Parkinson's disease}

\author{
D E Riley, T C Chelimsky
}

J Neurol Neurosurg Psychiatry 2003;74:56-60

See end of article for authors' affiliations

.....................

Correspondence to: Dr David Riley, Department of Neurology, University Hospitals of Cleveland, 11100 Euclid Ave Cleveland, Ohio 44106, USA;

david.riley@uhhs.com

Received 8 April 2002 In revised form 3 July 2002 Accepted 4 September 2002
Background: Formal laboratory testing of autonomic function is reported to distinguish between patients with Parkinson's disease and those with multiple system atrophy (MSA), but such studies segregate patients according to clinical criteria that select those with autonomic dysfunction for the MSA category.

Objective: To characterise the profiles of autonomic disturbances in patients in whom the diagnosis of Parkinson's disease or MSA used criteria other than autonomic dysfunction.

Methods: 47 patients with parkinsonism and autonomic symptoms who had undergone autonomic laboratory testing were identified and their case records reviewed for non-autonomic features. They were classified clinically into three diagnostic groups: Parkinson's disease (19), MSA (14), and uncertain (14). The performance of the patients with Parkinson's disease was compared with that of the MSA patients on five autonomic tests: RR variation on deep breathing, heart rate changes with the Valsalva manoeuvre, tilt table testing, the sudomotor axon reflex test, and thermoregulatory sweat testing.

Results: None of the tests distinguished one group from the other with any statistical significance, alone or in combination. Parkinson's disease and MSA patients showed similar patterns of autonomic dysfunction on formal testing of cardiac sympathetic and parasympathetic, vasomotor, and central and peripheral sudomotor functions.

Conclusions: This study supports the clinical observation that Parkinson's disease is often indistinguishable from MSA when it involves the autonomic nervous system. The clinical combination of parkinsonism and dysautonomia is as likely to be caused by Parkinson's disease as by MSA. Current clinical criteria for Parkinson's disease and MSA that direct patients with dysautonomia into the MSA group may be inappropriate.
S udies of autonomic function comparing patients with Parkinson's disease and multiple system atrophy (MSA) have reported differences between the two diseases in cardiovascular, ${ }^{1-3}$ urinary, ${ }^{4-6}$ anorectal, ${ }^{7}$ and skin temperature and sweating regulatory functions. ${ }^{1-3} 89$ These studies segregated patients with parkinsonism according to clinical diagnostic criteria, either published ${ }^{10-16}$ or devised ad hoc, ${ }^{46}$ into clinically probable MSA or Parkinson's disease depending on the presence of overt dysautonomia. This process virtually ensured that patients diagnosed with MSA would have more autonomic dysfunction by laboratory testing than those diagnosed with Parkinson's disease. Thus these studies completed a circular argument: parkinsonian patients with symptoms and signs of dysautonomia are designated as having MSA, then subsequent formal autonomic studies show greater dysfunction in MSA patients than in those with Parkinson's disease. Pathological studies, however, demonstrate that Parkinson's disease can cause profound global dysfunction of the autonomic nervous system, identical to that considered characteristic of MSA. ${ }^{17-24}$ Thus segregation into Parkinson's disease or MSA diagnostic categories on the basis of clinical dysautonomia appears unfounded. No study has assessed whether the two diseases manifest real differences in the type or degree of autonomic dysfunction if they are diagnosed by means other than symptomatically overt dysautonomia. Such an analysis is clinically relevant, as differentiating the two diseases is difficult when parkinsonism and autonomic dysfunction are both prominent.

We divided patients into Parkinson's disease and MSA groups according to clinical criteria that did not include autonomic dysfunction. We then analysed their formal autonomic studies to determine differences between Parkinson's disease and MSA. We hoped to determine whether laboratory evalua- tion of autonomic function truly helps in distinguishing Parkinson's disease from MSA in individual patients with parkinsonism.

\section{METHODS}

\section{Patient selection}

We searched the University Hospitals of Cleveland autonomic laboratory database for patients referred with a diagnosis or clinical information containing the key words "parkinsonism," "Parkinson's disease," and "multiple system atrophy." All patients had undergone laboratory testing because of symptoms suggestive of dysautonomia. The entire clinical record of each patient, compiled by a movement disorders specialist (DER), was reviewed for the occurrence of the clinical features listed in table 1 . After the review of their records, the patients were classified into Parkinson's disease or MSA groups according to nonautonomic features shown to be indicative of, or inconsistent with, each disease by clinicopathological correlation studies. Table 1 lists under the heading "Criteria for diagnosis of Parkinson's disease" various clinical features found to be characteristic of Parkinson's disease and unusual in MSA, and under "Criteria for diagnosis of MSA," various clinical findings associated with MSA rather than Parkinson's disease. Patients who did not meet criteria for either diagnosis, or met criteria for both, were placed in an "uncertain" category.

\section{Autonomic testing}

Autonomic testing was conducted according to standard clinical methods. ${ }^{39}$ Patients were contacted beforehand and instructed to discontinue, if relevant, fludrocortisone or midodrine (ProAmatine) five days before their laboratory evaluations, and withhold antiparkinsonian drug treatment on the 
Table 1 Clinical diagnostic criteria

\begin{tabular}{|c|c|}
\hline $\begin{array}{l}\text { Criteria for diagnosis of } \\
\text { Parkinson's disease }\end{array}$ & $\begin{array}{l}\text { Criteria for diagnosis of } \\
\text { multiple system atrophy }\end{array}$ \\
\hline $\begin{array}{l}\text { Patients must have a history, or } \\
\text { show three or more, of the following } \\
\text { clinical features, including at least } \\
\text { two of those marked by an asterisk }\end{array}$ & $\begin{array}{l}\text { Patients must have a history, or } \\
\text { show two or more, of the } \\
\text { following clinical features }\end{array}$ \\
\hline Rest tremor $* 25-27$ & Dysarthria ${ }^{35}$ \\
\hline Asymmetrical onset ${ }^{* 26} 28-30$ & Dysphagia $^{31}$ \\
\hline Preserved postural stability $\star 3132$ & Facial/cervical dystonia ${ }^{2535-37}$ \\
\hline $\begin{array}{l}\text { Typical levodopa responsiveness } * 26 \\
293133\end{array}$ & Action myoclonus ${ }^{35}$ \\
\hline Typical dyskinesias $* 2528$ & Stridor/vocal cord palsy 253538 \\
\hline Dementia*252831 & Hand contractures $^{25}$ \\
\hline Cognitive fluctuations ${ }^{34}$ & Corticospinal tract signs ${ }^{25} 35$ \\
\hline \multirow[t]{3}{*}{ Psychosis ${ }^{223031}$} & Gait ataxia $^{35}$ \\
\hline & Limb ataxia ${ }^{35}$ \\
\hline & Nystagmus 35 \\
\hline
\end{tabular}

Exclusion criterion: ataxia of limb or Exclusion criterion: dementia ${ }^{31}$ gait

day of testing. All patients underwent four tests, three of cardiovascular autonomic function (cardiac response to deep breathing, cardiovascular response to the Valsalva manoeuvre, and cardiovascular response to upright tilt) and one of sudomotor function (the axon reflex sweating test). Some patients underwent an additional test of sudomotor function, the thermoregulatory sweat test, if diagnostic questions remained and physical fitness permitted.

All tests of cardiovascular function used electrocardiographic recording and continuous beat to beat blood pressure monitoring with a photoplethysmograph. In addition, the last two studies also employed an intermittent automated blood pressure measurement every 60 seconds.

The deep breathing response was done in the supine position with the patient breathing slowly, evenly, and deeply at six breaths a minute for one minute. Recordings were repeated once. The best five (of 12) responses were averaged to yield the final result.

The response to the Valsalva manoeuvre was assessed twice, using 15 seconds of intrathoracic pressure against a mercury manometer at $40 \mathrm{~mm} \mathrm{Hg}$. Lesser pressures were accepted and the norms reduced accordingly by $20 \%$ per $10 \mathrm{~mm} \mathrm{Hg}$. The Valsalva ratio was calculated by dividing the heart rate in phase II by the heart rate in phase IV.
Tilt table testing was done at $90^{\circ}$ from horizontal for 10 to 20 minutes, after 20 minutes in the supine position.

The axon reflex test used $10 \%$ acetylcholine iontopheresed in five sites (dorsum of both feet, lateral calf, dorsum of the hand, and forearm) using $2 \mathrm{~mA}$ direct current for five minutes. Sweat output was recorded for this time and for an additional five minutes using a thermal conductivity based device.

The thermoregulatory sweat test employed an environment of $50 \%$ humidity and $50^{\circ} \mathrm{C}$ (skin at $40^{\circ} \mathrm{C}$ ) for 30 minutes, or when core temperature had increased by more than $1.5^{\circ} \mathrm{C}$. Sweat output was quantitated as for the axon reflex test, and an alizarin-red-S based marker for sweat was used to quantitate the geographical pattern of anhidrosis.

\section{Statistical analysis}

The review of the patients' clinical records and patient group assignments were completed independently of and before the statistical analysis of laboratory results. Autonomic test results were judged normal or abnormal by comparison with normal value ranges for comparable demographic categories. Data were compared across the two patient groups using a two tailed Student $t$ test with expected probability $(\mathrm{p})$ value for significance corrected to 0.1 by the Bonferroni method.

\section{RESULTS}

We reviewed 47 patients' records. Fourteen patients were given an uncertain diagnosis owing to insufficient clinical data to qualify for either Parkinson's disease or MSA $(n=11)$, sufficient features to warrant a diagnosis of Parkinson's disease in the presence of gait ataxia $(n=2)$, or mixed features of Parkinson's disease and MSA (three Parkinson's disease features and four MSA features) $(n=1)$. Fourteen patients were diagnosed with MSA, with a mean (SD) age of 66 (6.0) years and disease duration of 5.7 (3.8) years. Nineteen patients with Parkinson's disease had a mean age of 69 (9.9) years and a disease duration of 5.8 (4.0) years.

Abnormal results on individual tests occurred in a majority of patients in each group (table 2). Only one patient (who had Parkinson's disease) had no classic autonomic abnormalities (that is, normal deep breathing and Valsalva manoeuvre, no orthostatic hypotension or tachycardia on tilt, and a normal axon reflex test). However, upright tilt increased his blood pressure by $50 / 26 \mathrm{~mm} \mathrm{Hg}$, and thermoregulatory sweat testing was not done. Whenever the thermoregulatory sweat test was undertaken, it was abnormal in all tested patients from both

\begin{tabular}{|c|c|c|c|}
\hline Test & MSA & PD & t Test \\
\hline \multicolumn{4}{|l|}{ Deep breathing } \\
\hline Patients with abnormal results & $11 / 13(84.6 \%)$ & $13 / 19(68.4 \%)$ & NS \\
\hline $\begin{array}{l}\text { Average heart rate variation below } \\
\text { expected* }\end{array}$ & 4.18 beats $/ \mathrm{min}$ & 4.15 beats $/ \mathrm{min}$ & \\
\hline \multicolumn{4}{|l|}{ Valsalva manoeuvre } \\
\hline Patients with abnormal results & $5 / 8(62.5 \%)$ & $14 / 18$ (77.8\%) & NS \\
\hline Average Valsalva ratio below expected* & 0.135 & 0.131 & \\
\hline \multicolumn{4}{|l|}{ Tilt table testing } \\
\hline Patients with abnormal results & $10 / 13(76.9 \%)$ & $16 / 18(88.8 \%)$ & NS \\
\hline Average decrease of systolic blood pressure* & $47 \mathrm{~mm} \mathrm{Hg}$ & $55 \mathrm{~mm} \mathrm{Hg}$ & \\
\hline \multicolumn{4}{|l|}{ Sudomotor axon reflex } \\
\hline Patients with abnormal results & $10 / 14(71.4 \%)$ & $15 / 19$ (78.9\%) & NS \\
\hline $\begin{array}{l}\text { Average \% of sites with low or absent } \\
\text { sweating }^{*}\end{array}$ & $70.7 \%$ & $62.5 \%$ & \\
\hline Thermoregulatory sweat test & $8 / 8(100 \%)$ & $8 / 8(100 \%)$ & NS \\
\hline
\end{tabular}



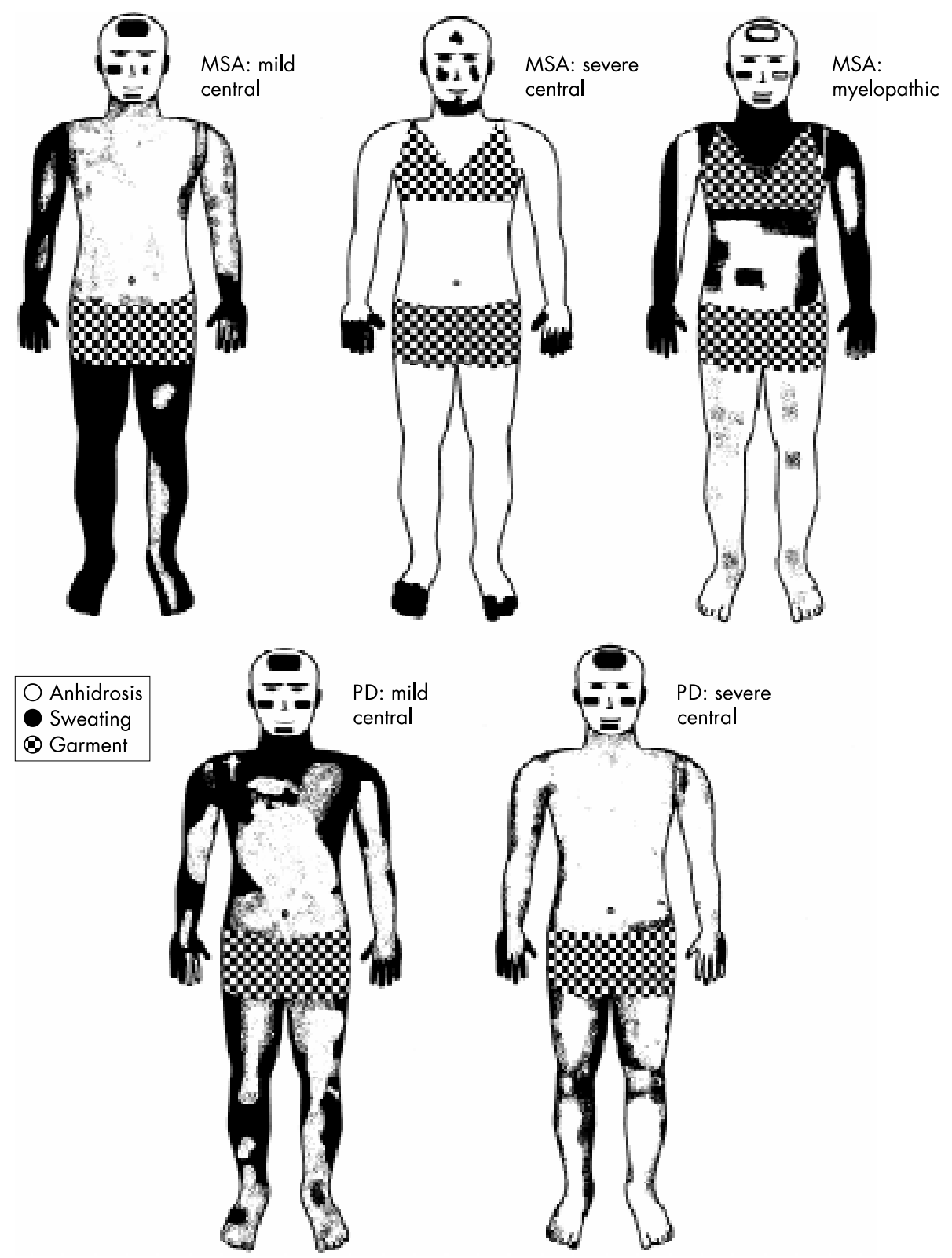

Figure 1 Thermoregulatory sweat patterns in five typical subjects (three with multiple system atrophy (MSA); two with Parkinson's disease (PD)). The patterns were similar in the two groups, and most commonly showed a "central" distribution of anhidrosis involving the thoracic and proximal limb regions disproportionately more than the distal acral areas.

groups. Figure 1 shows typical findings. One patient in each group had a classic myelopathic pattern, at the mid-thoracic level. We found an abnormal axon reflex sweat test in the same proportion of patients in both groups.

No individual test distinguished the two groups of patients, either by the frequency or by the magnitude of abnormal results (table 2). Pairing the two tests showing the greatest disparity between the two groups (the trend toward an abnormal response to deep breathing with a normal response to the Valsalva manoeuvre in the MSA group, table 2) did not prove statistically significant in distinguishing the two groups.

Of note in the MSA group, there appeared to be a discrepancy between vital sign changes on tilt table testing and symptoms suggestive of hypotension, some patients being more symptomatic than expected and others less. None of the four MSA patients with a systolic blood pressure fall of $\geqslant 50$ $\mathrm{mm} \mathrm{Hg}$ had symptoms of hypotension, whereas five of the seven whose systolic pressure fell by $\leqslant 30 \mathrm{~mm} \mathrm{Hg}$ experienced such symptoms. In comparison, in the Parkinson's disease group, three of 10 patients with a blood pressure fall of $\geqslant 50$ $\mathrm{mm} \mathrm{Hg}$ had no symptoms, while three of the four patients with a blood pressure fall of $\leqslant 30 \mathrm{~mm} \mathrm{Hg}$ had orthostatic symptoms. In summary, nine of 11 MSA patients had symptoms that did not correlate with expectations based on vital sign changes, compared with six of 14 Parkinson's disease patients. The difference constituted only a trend towards statistical significance $(\mathrm{p}=0.05)$.

Some patients were unable to complete one or more segments of the test battery. Inability to perform the Valsalva manoeuvre occurred more often in the MSA group $(p<0.01)$.

\section{DISCUSSION}

We sought to study autonomic function in Parkinson's disease and MSA patients after attempted elimination of selection bias based upon the degree of symptomatic dysautonomia. We studied a group of parkinsonian patients with dysautonomia and segregated them according to those clinical features (other than autonomic dysfunction) that had previously been 
shown in clinicopathological studies to be more characteristic of either Parkinson's disease or MSA (table 1). We were unable to find any distinguishing characteristics in the profiles of their deficits on the autonomic test battery employed (table 2). Our results indicate that formal testing of autonomic function cannot distinguish between patients with Parkinson's disease and MSA who have autonomic symptoms when the presence of such symptoms is not included in the diagnostic criteria. We cannot exclude the possibility that this finding resulted from an inadequate sample size. However, our results support anecdotal observations that the pattern of autonomic dysfunction in Parkinson's disease mimics that of MSA, and that autonomic studies cannot distinguish the two. ${ }^{15}$

We do not know how widespread is the arbitrary designation of the combination of parkinsonism and dysautonomia as MSA in clinical practice. However, two reports on autonomic function in Parkinson's disease and MSA where diagnosis was based on postmortem confirmation are instructive. In one, a majority of the patients with Parkinson's disease and clinical dysautonomia was misdiagnosed as having MSA. ${ }^{24}$ In the other, none of 10 MSA patients (from a cohort of 33 patients) who were clinically misdiagnosed as Parkinson's disease had autonomic problems at disease onset, while $46 \%$ of the correctly diagnosed MSA patients $\operatorname{did} .^{40}$ Interestingly, in the latter study a retrospective review found that $76 \%$ of 135 patients with Parkinson's disease had some degree of autonomic dysfunction during life, despite the observation by the investigators that the case records of patients correctly diagnosed premortem with MSA showed more diligent searches for autonomic symptoms than those of Parkinson's disease patients. This figure is comparable to the $74 \%$ frequency of autonomic dysfunction in 203 pathologically proven cases of MSA in Wenning et al's review. ${ }^{25}$

Our results cannot be used as epidemiological data describing the frequency of autonomic disturbances in Parkinson's disease or MSA, as all the patients were selected for laboratory study on the basis of autonomic symptoms. As the prevalence of Parkinson's disease appears to be many times that of MSA $^{14}{ }^{14}$ the relatively equal proportions of our two patient groups support the notion that autonomic disturbances are indeed more common in MSA than in Parkinson's disease. ${ }^{26}$ Thus an absence of dysautonomia in a patient with parkinsonism suggests the diagnosis of Parkinson's disease. However, our study also indicates that, in an individual patient, the combination of parkinsonism and dysautonomia is at least as likely to result from Parkinson's disease as MSA.

Current clinical diagnostic criteria allow for considerable overlap between Parkinson's disease and MSA. One consequence is that many MSA patients appear indistinguishable from those with Parkinson's disease, even up to death. ${ }^{14}{ }^{41}$ Correspondingly, patients with Parkinson's disease may present a clinical picture identical to that of MSA. ${ }^{17-24}$ Confusion arises chiefly because both diseases can lead to a combination of parkinsonism and dysautonomia. A means of distinguishing between the two conditions other than by existing clinical criteria is needed, as segregation of patients according to the presence or absence of dysautonomia appears to be inadequate and inappropriate.

Finally, some of our laboratory observations warrant further comment. The universal abnormality of thermoregulatory sweat test in both patient groups suggests that this test may be the most sensitive one for autonomic involvement in both Parkinson's disease and MSA, but the number of patients tested was small. The patterns of anhidrosis were similar in the two groups (fig 1), ranging from the expected "central pattern" which was most common, to segmental, and myelopathic, shown by one patient in each group. This wide spectrum of anhidrotic patterns implies that initial involvement and progression of autonomic system cellular loss varies considerably. The comparable abnormality of axon reflex testing suggests ganglionic or postganglionic involvement in the majority of patients in both groups. Rajput and Rozdilsky attributed dysautonomia in Parkinson's disease to neuronal loss and Lewy body formation in sympathetic ganglia, ${ }^{42}$ while Bannister and Oppenheimer correlated dysautonomia in MSA with degeneration of the intermediolateral cell column of the spinal cord. ${ }^{43}$ However, our results are consistent with reports of impaired postganglionic sympathetic function demonstrated by impaired sweat axon reflexes in MSA patients. ${ }^{39} 44$ The seemingly paradoxical relation between symptoms and signs that we found on tilt table testing, particularly striking in the MSA group, deserves further exploration in the future. Other investigators have noted a lack of symptoms in MSA patients with orthostatic hypotension. ${ }^{45}$ MSA patients may be quite symptomatic early in their disease course, but may lose the ability to develop orthostatic symptoms when vasomotor failure is advanced.

\section{ACKNOWLEDGEMENTS}

DER is supported by the Evans Foundation, the estate of Nina Kramer, and the Gift of Nina and Sandy McAfee. We thank Robert B Daroff MD for reviewing the manuscript.

\section{Authors' affiliations}

D E Riley, T C Chelimsky, Department of Neurology, University Hospitals of Cleveland and Case Western Reserve University School of Medicine, Cleveland, Ohio, USA

Competing interests: none declared

\section{REFERENCES}

1 Holmberg B, Kallio M, Johnels B, et al. Cardiovascular reflex testing contributes to clinical evaluation and differential diagnosis of Parkinsonian syndromes. Mov Disord 2001;16:217-25.

2 Bordet R, Benhadjali J, Destee A, et al. Sympathetic skin response and R-R interval variability in multiple system atrophy and idiopathic Parkinson's disease. Mov Disord 1996;11:268-72.

3 De Marinis M, Stocchi F, Gregori B, et al. Sympathetic skin response and cardiovascular autonomic function tests in Parkinson's disease and multiple system atrophy with autonomic failure. Mov Disord 2000;15:1215-20.

4 Stocchi F, Carbone A, Inghilleri $M$, et al. Urodynamic and neurophysiological evaluation in Parkinson's disease and multiple system atrophy. J Neurol Neurosurg Psychiatry 1997;62:507-11.

5 Sakakibara R, Hattori T, Uchiyama T, et al. Videourodynamic and sphincter motor unit potential analyses in Parkinson's disease and multiple system atrophy. J Neurol Neurosurg Psychiatry 2001;71:600-6.

6 Bonnet AM, Pichon J, Vidailhet M, et al. Urinary disturbances in striatonigral degeneration and Parkinson's disease: clinical and urodynamic aspects. Mov Disord 1997;1 2:509-13.

7 Stocchi F, Badiali D, Vacca L, et al. Anorectal function in multiple system atrophy and Parkinson's disease. Mov Disord 2000;15:71-6.

8 Klein C, Brown R, Wenning G, et al. The "cold hands sign" in multiple system atrophy. Mov Disord 1997;12:514-18.

9 Pierangeli G, Provini F, Maltoni P, et al. Nocturnal body core temperature falls in Parkinson's disease but not in multiple-system atrophy. Mov Disord 2001;16:226-32.

10 Gilman S, Low PA, Quinn N, et al. Consensus statement on the diagnosis of multiple system atrophy. J Auton Nerv Syst 1998;74:189-92

11 Gilman S, Low PA, Quinn N, et al. Consensus statement on the diagnosis of multiple system atrophy. J Neurol Sci 1999;163:94-8.

12 Gelb DJ, Oliver E, Gilman S. Diagnostic criteria for Parkinson disease. Arch Neurol 1999;56:33-9.

13 Gibb WR, Lees AJ. The relevance of the Lewy body to the pathogenesis of idiopathic Parkinson's disease. J Neurol Neurosurg Psychiatry 1988;51:745-52.

14 Hughes AJ, Daniel SE, Kilford L, et al. Accuracy of clinical diagnosis of idiopathic Parkinson's disease: a clinico-pathological study of 100 cases. J Neurol Neurosurg Psychiatry 1992;55:181-4.

15 Quinn N. Multiple system atrophy - the nature of the beast. J Neurol Neurosurg Psychiatry 1989;suppl:78-89.

16 Quinn N. Multiple system atrophy. In: Marsden CD, Fahn S, eds. Movement disorders 3. Oxford: Butterworth-Heinemann, 1994:262-81.

17 Kono C, Matsubara M, Inagaki T. Idiopathic orthostatic hypotension with numerous Lewy bodies in the sympathetic ganglia. Report of a case. Neurol Med Jpn 1976;4:568-70.

18 Yoshimura $M$, Shimada $H$, Nagura $H$, et al. Two autopsy cases of Parkinson's disease with Shy-Drager syndrome. Trans Soc Pathol Jpn 1980;69:432.

19 Pakiam AS, Bergeron C, Lang AE. Diffuse Lewy body disease presenting as multiple system atrophy. Can J Neurol Sci 1999;26:127-31. 
20 de Vos RA, Jansen EN, Stam FC, et al. "Lewy body disease": clinico-pathological correlations in 18 consecutive cases of Parkinson's disease with and without dementia. Clin Neurol Neurosurg 1995; $97: 13-22$

21 Burkhardt CR, Filley CM, Kleinschmidt-DeMasters BK, et al. Diffuse Lewy body disease and progressive dementia. Neurology 1988;38:1520-8.

22 Kosaka K. Diffuse Lewy body disease in Japan. J Neurol 1990;237: 197-204.

23 Kuzuhara S, Yoshimura M. Clinical and neuropathological aspects of diffuse Lewy body disease in the elderly. Adv Neurol 1993:60:464-9.

24 Benarroch EE, Schmeichel AM, Parisi JE. Involvement of the ventrolateral medulla in parkinsonism with autonomic failure. Neurology 2000;54:963-8.

25 Wenning GK, Tison F, Ben Shlomo Y, et al. Multiple system atrophy: a review of 203 pathologically proven cases. Mov Disord 1997:12:133-47.

26 Colosimo C, Albanese A, Hughes A, et al. Some specific clinical features differentiate multiple system atrophy (striatonigral variety) from Parkinson's disease. Arch Neurol 1995;52:294-8.

27 Rajput AH, Rozdilsky B, Ang L. Occurrence of resting tremor in Parkinson's disease. Neurology 1991:41:1298-9.

28 Hughes AJ, Ben-Shlomo Y, Daniel SE, et al. What features improve the accuracy of clinical diagnosis in Parkinson's disease: a clinicopathologic study. Neurology 1992;42:1142-6.

29 Hughes AJ, Daniel SE, Blankson S, et al. A clinicopathologic study of 100 cases of Parkinson's disease. Arch Neurol 1993;50:140-8.

30 Hely MA, Reid WG, Halliday GM, et al. Diffuse Lewy body disease: clinical features in nine cases without coexistent Alzheimer's disease. $J$ Neurol Neurosurg Psychiatry 1996;60:531-8.

31 Wenning GK, Ben-Shlomo Y, Hughes A, et al. What clinical features are most useful to distinguish definite multiple system atrophy from Parkinson's disease? J Neurol Neurosurg Psychiatry 2000;68:434-40.

32 Wenning GK, Scherfler C, Granata R, et al. Time course of symptomatic orthostatic hypotension and urinary incontinence in patients with postmortem confirmed parkinsonian syndromes: a clinicopathological study. J Neurol Neurosurg Psychiatry 1999;67:620-3.
33 Raiput AH, Rozdilsky B, Rajput A, et al. Levodopa efficacy and pathological basis of Parkinson syndrome. Clin Neuropharmacol 1990;13:553-8.

34 Byrne EJ, Lennox G, Lowe J, et al. Diffuse Lewy body disease: clinical features in 15 cases. J Neurol Neurosurg Psychiatry 1989;52:709-17.

35 Wenning GK, Ben-Shlomo Y, Magalhaes M, et al. Clinicopathological study of 35 cases of multiple system atrophy. I Neurol Neurosurg Psychiatry 1995;58:160-6.

36 Quinn N. Disproportionate antecollis in multiple system atrophy. Lancet 1989;i:844.

37 Wenning GK, Quinn NP, Daniel SE, et al. Facial dystonia in pathologically proven multiple system atrophy. Mov Disord 1996; 11:107-9.

38 Hayashi $M$, Isozaki E, Oda $M$, et al. Loss of large myelinated nerve fibres of the recurrent laryngeal nerve in patients with multiple system atrophy and vocal cord palsy. J Neurol Neurosurg Psychiatry 1997;62:234-8

39 Low PA. Clinical autonomic disorders : evaluation and management Philadelphia: Lippincott-Raven, 1997.

40 Magalhaes M, Wenning GK, Daniel SE, et al. Autonomic dysfunction in pathologically confirmed multiple system atrophy and idiopathic Parkinson's disease - a retrospective comparison. Acta Neurol Scand 1995;91:98-102.

41 Rajput AH, Rozdilsky B, Rajput A. Accuracy of clinical diagnosis in parkinsonism - a prospective study. Can J Neurol Sci 1991;18:275-8.

42 Rajput AH, Rozdilsky B. Dysautonomia in Parkinsonism: a clinicopathological study. J Neurol Neurosurg Psychiatry 1976;39:1092-100.

43 Bannister R, Oppenheimer DR. Degenerative diseases of the nervous system associated with autonomic failure. Brain 1972:95:457-74.

44 Cohen J, Low P, Fealey R, et al. Somatic and autonomic function in progressive autonomic failure and multiple system atrophy. Ann Neurol 1987;22:692-9.

45 Mathias CJ, Mallipeddi R, Bleasdale-Barr K. Symptoms associated with orthostatic hypotension in pure autonomic failure and multiple system atrophy. J Neurol 1999;246:893-8. 